Check for updates

, London, UK

Correspondence to: T Richards Trichards@bmj.com Cite this as: BMJ 2021;373:n1225 http://dx.doi.org/10.1136/bmi.n1225 Published: 19 May 2021

\section{Healthcare decision making should be democratised}

\section{Post-pandemic health reforms should prioritise wide public and patient consultation and collaboration Tessa Richards, Henry Scowcroft, Emma Doble, Amy Price, Kamran Abbasi}

The covid-19 pandemic has precipitated radical changes in healthcare practices and highlighted outdated ways of working that are not fit for purpose in the digital age. It also stalled progress on shared decision making and patient and public involvement in healthcare. Early in the pandemic, well embedded structures for involvement were suddenly disrupted ${ }^{1}$ at a time when the concerns of patients and the public could scarcely have been greater.

In response, patient advocates, organisations, and civil society groups in many countries have worked in overdrive, supporting their communities, ${ }^{2}$ collating information about the nature and impact of the pandemic, and urging policy makers to heed the findings ${ }^{3} 4$ and work collaboratively with them to develop new inclusive and equitable policies. ${ }^{5}$

The devastating health, social, and economic effects of the pandemic, in rich and poor countries alike, strengthens the call for wider patient and public participation in policy making and research. This call is being endorsed by the World Health Organization ${ }^{67}$ and facilitated by increasing participation in virtual meetings. ${ }^{8}$ Responding to the huge challenges countries currently face requires sharing expertise, experiential knowledge, and new approaches to involving patients and the public in research. ${ }^{9}$

The BMJ has advocated for partnership with patients and the public for decades, ${ }^{10}$ and seven years ago we launched a formal patient and public partnership strategy (https://www.bmj.com/campaign/patientpartnership). This has fundamentally changed how we work-and think. Patient review of research has become the norm, as has inviting patients and carers to co-write and comment on articles. In 2019-20, over $80 \%$ of research papers were reviewed by patients, and $85 \%$ of commissioned educational articles were co-produced with patients and patient advocates. Our feedback suggests that encouraging authors to involve patients and patient advocates in the development of their articles has influenced professional mindsets and broadened the relevance and reach of our content.

We are delighted that other medical journals, in addition to many in BMJ's portfolio of specialist journals, have taken up key elements of our strategy, ${ }^{11}$ particularly the requirement for research submissions to include a formal patient and public involvement statement. We owe much to the support and agenda setting role of our international patient and public advisory panel. Its input regularly informs editorial commissioning decisions and longer term strategy.

\section{Next steps}

As the world confronts the shocks and aftershocks of the pandemic, we find ourselves asking, what next? TheBMJ continues to chart and comment on the effects of the pandemic, publish new research findings, extend professional and public debate on key concerns, and advocate for equitable access to healthcare and more collaborative working. We recently worked with WHO on a collection of articles focusing on the need for knowledge to be co-produced ${ }^{12}$ and increased our interaction with national, European, and international policy making bodies and patient organisations. We are also committed to spur discussion on how to develop more robust and sustainable structures for patient and public involvement in healthcare despite scant resources, training, and support.

In response to input from our patient and public advisory panel, we have decided to focus on two areas over the coming year. Firstly, as systems look to adapt and rebuild, we seek to identify, discuss, and disseminate initiatives that involve patients and the public in service reconfiguration and healthcare innovation. There is an opportunity, as well as an ethical imperative, to adopt creative approaches to co-design and the evaluation of new models of care. There is no universal solution, and we seek to spread learning from effective initiatives in different countries and settings and welcome suggestions for contributions to the Partnership in Practice series. ${ }^{13}$

Secondly, recognising the digital and data driven world we live in, we will advocate more strongly in support of a key principle: that healthcare systems should provide patients with real time online access to all their health information and data. In the US a new law has just mandated this, and evidence of the benefit it brings to both patients and health systems is growing. ${ }^{14}$ Access to personal health records, and their use to promote self-management and improve communication with health professionals, will entail clearing substantial cultural and educational hurdles as well as technological and organisational ones. To chart international developments on patients' access to records, we are publishing a collection of articles ${ }^{15}$ and working with an international interdisciplinary group to set up a series of webinars to debate key questions around health records, including access, understanding, sharing, control, and use.

The pandemic has shown that we live in an interdependent world but also how easily patient and public voices and preferences can be lost. Personal health, public health, and environmental sustainability depend on ensuring policy makers acknowledge that all voices count and are listened to. 
Competing interests: We have read and understood BMJ policy on declaration of interests and have no interests to declare.

Provenance and peer review: Commissioned; not externally peer reviewed.

We thank the members of our patient and public advisory panel (https://www.bmj.com/aboutbmi/advisory-panels/patient-panel-members) for their input and support for this editorial.

1 Richards T, Scowcroft HBMJ's international patient and public advisory panel. Patient and public involvement in covid-19 policy making. BMJ2020;370:m2575.

doi: 10.1136/bmj.m2575 pmid: 32611571

2 Volunteers are filling the gaps in India's fight against covid-19. Economist 2021 May.

https://www.economist.com/asia/2021/05/01/volunteers-are-filling-the-gaps-in-indias-fightagainst-covid-19

3 Lawler M. Cancer must not be the forgotten "C" in the fight against covid-19. BMJ Opinion, 11 May 2021. https://blogs.bmj.com/bmj/2021/05/11/cancer-must-not-be-the-forgotten-c-in-thefight-against-covid-19/

4 National Voices. Submission to Health and Social Care Select Committee white paper integration and innovation: working together to improve health and social care for all. 2021.

https://www.nationalvoices.org.uk/publications/our-publications/submission-health-and-socialcare-select-committee-white-paper

5 Murphy E, Tierney E, Ní Shé É, etalPPI Ignite @ NUI Galway Public Advisory Panel. COVID-19: Public and patient involvement, now more than ever. HRB Open Res 2020;3:35. doi: 10.12688/hrbopenres.13067.1. pmid: 32666039

6 WHO. Nothing for us without us. https://apps.who.int/iris/bitstream/handle/10665/340737/9789240023321-eng.pdf?sequence=1\&isAllowed=y

7 WHO. Handbook for social participation for UHC. https://country-matrix-repository.app.box.com/s/tu72xz1406fpy1zsyh77evf4nnh90oym

8 Doble E. WHO global diabetes compact-inviting people living with diabetes to sit at the table. BMJ Opinion, 1 Apr 2021. https://blogs.bmj.com/bmj/2021/04/01/emma-doble-who-global-diabetes-compact-inviting-people-living-with-diabetes-to-sit-at-the-table/

9 NHS Health Research Authority. Public involvement in a pandemic: lessons from the UK COVID-19 public involvement matching service. Updated 28 Jan 2021. https://www.hra.nhs.uk/planningand-improving-research/best-practice/public-involvement/public-involvement-pandemic-lessonsuk-covid-19-public-involvement-matching-service/\#conclusions

10 Coulter A. Paternalism or partnership? Patients have grown up - and there's no going back. BMJ 1999;319:719-20. doi: 10.1136/bmj.319.7212.719 pmid: 10487980

11 Richards T, Schroter S, Price A, Godlee F. Better together: patient partnership in medical journals. BMJ2018;362:k3798. doi: 10.1136/bmj.k3798 pmid: 30201610

12 Increasing the impact of health research through co-production of knowledge. BM/2021 https://www.bmj.com/co-producing-knowledge

13 BMJ partnership in practice series. https://www.bmj.com/content/partnership-practice

14 Salmi L, Blease C, Hägglund M, Walker J, DesRoches CM. US policy requires immediate release of records to patients. BMJ 2021;372:n426. doi: 10.1136/bmj.n426 pmid: 33602667

15 Patient access to health records. BM/nttps://www.bmj.com/content/patient-access-health-records 